\title{
Mechanical Properties of Vacuum-Sintered Yttria Ceramics
}

\author{
DISCLAIMER
}

This report was prepared as an account of work sponsored by an agency of the United States Government. Neither the United States Government nor any agency thereof, nor any of their employees, makes any warranty, express or implied, or assumes any legal liability or responsibility for the accuracy, completeness, or usefulness of any information, apparatus, product, or process disclosed, or represents that its use would not infringe privately owned rights. Reference herein to any specific commercial product, process, or service by trade name, trademark, manufacturer, or otherwise does not necessarily constitute or imply its endorsement, recommendation, or favoring by the United States Government or any agency thereof. The views and opinions of authors expressed herein do not necessarily state or reflect those of the United States Government or any agency thereof. \section{ARUN S. WAGH, " DARREL ROBERTS, TAYYAB SURATWALA, MICHAEL
MCMANN and ROGER B. POEPPEL" \\ Materials and Components Technology Division, Argonne National Laboratory, 9700 S. Cass Avenue, Argonne, IL 60439*}

- Members, American Ceramics Society
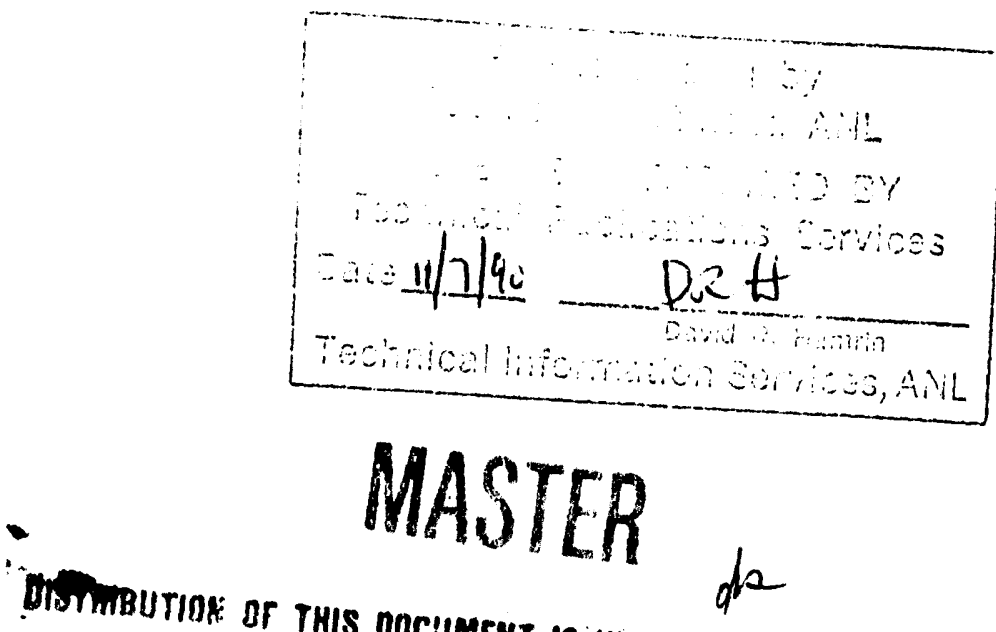
Mechanical properties of vacuum sintered dense yttria ceramics have been studied. Values of flexural strength, fracture toughness and thermal shock behavior, better than those reported in the literature, are reported. Microscopic investigations reveal elastic strain energy and cleavage step formation as the major contributors to the fracture energy. 
Ceramics of oxides and compounds of low free energy of formation and refractory metals are the most suitable candidates as container materials for various pyrochemical processes, due to their thermodynamic stability and corrosion resistance. Ceramics, however, may be prefered over refractory metals for fabrication of large containers due to their light weight.

Yttria is one of the oxides for such applications. Its free energy of formation at $1000 \mathrm{~K}$ is $-128.64 \mathrm{kcal} / \mathrm{g}$-atom, which is lower than most of the oxides, nitrides, carbides and borides, and hence, may be considered as one of the most stable oxides in various chemical environments at that temperature. Because of this reason, this study is aimed at studying yttria ceramics for applications as a container material in pyrochemical processes.

There have been several attempts in the past to study the mechanical properties of yttria ceramics. Marlowe and Wilder $^{1}$ have reported elasticity and internal friction of porous yttria ceramics sintered in a helium atmosphere and induction furnace. Gogotsi ${ }^{2}$ has reported thermal shock behavior of air-sintered dense yttria. Kozlova et al., ${ }^{3}$ have vacuum sintered yttria at $2000-2200^{\circ} \mathrm{C}$ and obtained $98 \%$ density. Grain size dependence of fracture energy of vacuum sintered yttria has been investigated by Monroe and Smyth.4 Unfortunately, the vacuum sintered yttria contains a substochiometric phase as reported by Jollet et al. ${ }^{5}$ Solov'ena et al. ${ }^{6}$ have studied this phase. They show that a monoclinic phase is developed during sintering with a stochiometric composition $\mathrm{Y}_{2} \mathrm{O}_{2}$.9148, which disappears after refiring in air. For pyrochemical applications, it is essential to avoid such a second phase, and to develop containers, it is necessary to study mechanical and thermal behavior of the material beyond what has been 
reported in the literature. The present study is intended to provide such a data base.

Dense ceramics have been developed in this study by vacuum sintering and a subsequent air firing to oxidize the substochiometric phase back to yttria. Detailed mechanical properties and thermal shock behavior have been studied, and in both cases, we report improved mechanical properties in this study.

\section{FABRICATION OF SPECIMENS}

Commercial, chemical grade yttria powder supplied by Molycorp Louviers Company was used for the fabrication of the specimens. The particle size of the powder ranged from 2-10 $\mu \mathrm{m}$ with the median at $5.27 \mu \mathrm{m}$. The powder was mixed with $1 \%$ ammonium algenate, which is used as a binder, and ball milled for 16 hours. Bars of dimensions $44.45 \mathrm{~mm}$. X $7.75 \mathrm{~mm}$. X $3.45 \mathrm{~mm}$. were pressed at $9400 \mathrm{psi}$. They were bisque fired at $900^{\circ} \mathrm{C}$ for one hour.

The specimen bars were vacuum-sintered for two hours in a Brew furnace at $1680^{\circ} \mathrm{C}$. The pressure during sintering was down to $\approx 10^{-6}$ Torr. The bars were placed in a yttria bed to avoid any diffusion of tungsten from the platform of the furnace.

The bars were grayish and often pinkish in color. Following the study by Jollet et al., 5 it was clear that this was due to a substochiometric phase in the samples developed in the reducing atmosphere. The densities of the bars were measured by standard saturation water displacement. The bars 
were $93.9 \%$ dense. To oxidize the bars, they were placed in an air furnace and sintered at $1200^{\circ} \mathrm{C}$ for one hour. The bars now turned white with a further shrinkage. Thus, the final density of the bars was $94.7 \%$ of the theoretical density of $5.01 \mathrm{gm} / \mathrm{cm} .^{3}$

\section{MECHANICAL PROPERTIES}

The elastic modulus (E) of the specimens was measured by the sonic method. To get an insight into the fracture behavior of the material, both fracture toughness $\left(\mathrm{K}_{\mathrm{Ic}}\right)$ and the flexural strength $(\sigma)$ were measured, the former by diamond indentation technique and the latter by a four point bend test on an Instron Machine. The critical flaw size (c) was determined by the Griffith relation,

$$
\sigma=\frac{\mathrm{K}_{\mathrm{IC}}}{1.35 \sqrt{\mathrm{C}}}
$$

Table 1 presents the measured values of physical and mechanical properties. The bulk density of $94.7 \%$ of the theoretical density is comparable to the one obtained by previous workers ${ }^{7-8}$. Rasmussen et al.9 report better sinterability by using powder prepared from new hydroxide precurscr and obtain a density of $99.6 \%$. Considering the fact that the present method of fabrication yields hardly any open pores in the material, and the residual porosity is due to mainly closed pores, it is an appropriate 
method for the fabrication of container material, even at the density obtained in this work.

Table I. Physical and mechanical properties of vacuum sintered yttria

\begin{tabular}{lc}
\hline \multicolumn{1}{c}{ Property } & \multicolumn{1}{c}{ Measured value } \\
\hline Bulk density & $4.745 \mathrm{gms} / \mathrm{cm}^{3}(94.7 \%$ theoretical $)$ \\
Closed porosity & $0.265 \mathrm{gms} / \mathrm{cm}^{3}(5.3 \%)$ \\
Flexural strength & $75.56 \pm 7.5 \mathrm{MPa}$ \\
Fracture toughness & $1.58 \pm 0.03 \mathrm{MPa} \sqrt{\mathrm{m}}$ \\
Youngs modulus & $159 \pm 2 \mathrm{GPa}$ \\
Shear modulus & $611 \pm 7.6 \mathrm{GPa}$ \\
\hline \hline
\end{tabular}

The flexural strength is approximately $25 \%$ higher than that reported by Gogotsi ${ }^{2}$ for yttria of slightly higher densities. There have been no reported values of direct measurement of the fracture toughness. However, a comparison of our results with the fracture energy of Monroe and Smyth can be made. The fracture energy is calculated by using the formula: 


$$
\gamma=\frac{K_{I C}^{2}}{2 E}
$$

Using the measured values from Table 1 for $\mathrm{K}_{1 \mathrm{c}}$ and $\mathrm{E}$, we obtain $\approx 8$ Joules $/ \mathrm{m}^{2}$. This value is again about $30 \%$ higher than reported by Monroe and Smyth.

The modulus of elasticity measured by us has an average value of $159 \pm 2$ GPa. Marlowe and Wilder ${ }^{1}$ have measured the elastic modulus for porous yttria sintered in air at nearly the same temperature as ours. They report a linear fit given by

$$
\mathrm{E}=180[1-2.49 \mathrm{P}] \mathrm{GPa}
$$

where, $\mathrm{P}$ is the porosity of the material. Taking $\mathrm{P}=0.04$ for our material, this amounts to $\mathrm{E}=162 \mathrm{GPa}$. This is nearly the value obtained by direct measurement. Thus, the present results agree well with earlier studies on modulus of elasticity, but the fracture toughness and flexural strength are higher in the present case.

\section{THERMAL SHOCK RESISTANCE}

The thermal shock behavior of the specimens was measured by heating the bars in an air furnace for half an hour at the desired temperature to reach steady state. The bars were then dropped into water at room temperature. They were then dried and the flexural strength was measured. 
Figure 1 gives the flexural strength of the specimen as a function of the temperature drop. The strength increased slightly when the temperature was dropped from $200^{\circ} \mathrm{C}$ to room temperature. The strength, however, decreased rapidly between 200 and $300^{\circ} \mathrm{C}$. Beyond that temperature, the decrease is gradual, but small.

Gogotsi $^{2}$ has observed a similar behavior. Due to higher flexural strength in the material in our study, the strength in the entire range of the temperature drop is better. The transition temperature drop, where the material loses its strength rapidly, also is slightly higher in the present case. These factors indicate that the yttria ceramics fabricated in this work has improved mechanical properties.

\section{MICROSCOPIC INVESTIGATIONS AND DISCUSSION}

Figure 2 is a SEM micrograph of the fractured surface from the flexural strength measurement. Even though, clear grain structure is not visible, grains of the order of $10 \mu \mathrm{m}$ are identifiable. A fairly uniform distribution of pores of the order of $1 \mu \mathrm{m}$ size are also visible. They must be closed pores, as direct measurement by water intrusion indicates negligibly small open porosity. It is likely that this porosity is a result of oxygen release at the time of the growth of substochiometric phase in the material.

A close look at the fractured surface reveals the separation of grains due to intergranular fracture and cleavage step formations as the modes of fracture. However, it is unlikely that cleavage step formation will expend a large amount of energy. 10,11 As shown before, the fracture energy calculated from the fracture toughness data is $8 \mathrm{~J} / \mathrm{m}^{2}$, about one fourth that of elastic 
strain energy of alumina ceramics $\left(\approx 30 \mathrm{~J} / \mathrm{m}^{2}\right)$. 12 The elastic strain energy is proportional to $\mathrm{E}^{2}$. The elastic modulus of alumina is $280 \mathrm{GPa}$, which implies that, if all the fracture energy is elastic strain energy, and if the value of $E$ is calculated for yttria from this fracture energy, one should obtain the modulus of elasticity as approximately half of that of alumina. The measured value of $\mathrm{E}$ presented in Table 1 for yttria is $159 \mathrm{GPa}$, which is nearly half of that of alumina. This implies that, the major contribution to the surface energy of fracture in yttria arises from the elastic strain.

The critical-flaw size is $\approx 250 \mu \mathrm{m}$. This high value indicates that, there exists considerable scope to improve the strength of the material by reducing the flaw-size. A second phase in yttria may reduce the flaw-size. Experiments are underway to improve flexural strength and hence thermal shock behavior this way for applications as container materials for pyrochemical processes.

\section{Acknowledgements}

This work was supported by the U. S. Department of Energy, Nuclear Energy Research and Development Program, under Contract W-31-109-Eng-38. 


\section{REFERENCES}

1M. O. Marlowe and D. R. Wilder, "Elasticity and Internal Friction of Polycrystalline Yttrium Oxide”, J. Am. Ceram. Soc., 48, 227-233(1965)

2G. A. Gogotsi, Thermal Stress behavior of Yttria, Scandia and AlN Ceramics", Ceramurgia Int., 6[1], 31-35 (1980)

3A. E. Kozlova, E. S. Lukin and D. N. Poluboyavinov, "Effect of Dispersion of Pure Yttrium Oxide on Its Pressing and Sintering", Ogneupory, 7, 2226(1973)

4L. D. Monroe and J. R. Smyth, "Grain Size Dependence of Fracture Energy of $\mathrm{Y}_{2} \mathrm{O}_{3}{ }^{n}$, J. Am. Ceram. Soc., 61 [11-12], 538-539 (1978)

5Francois Jollet, Phillippe Maire, martine Gautier, Jean-Paul Duraud and Claude Le Gressus, J. Am. Ceram. Soc., 71 [9] C-396-C-398 (1988)

6A. E. Solov'eva、 K. K. Artemıva, L. A. Rudenko and A. E. Kipshidze, "Influence of High-Temperature Firing in Vacuum on the Structural Properties of Yttrium Oxide", Ogneupory, 10, 18-21(1985)

7Muhsin Ciftcioglu, Mufit Akinc and Lawrence Burkhart, "Measurement of Agglomerate Strength Distributions in Agglomerated Powders", Am. Ceram. Soc. Bull. 65[12] 1591-96 (1986)

8Daniel J. Sordelet and Mufit Akinc, "Sintering of Monosizes, Spherical Yttria Powders", J. Am. Ceram. Soc., 7[12], 1148-53 (1988) 
${ }^{9}$ M. D. Rasmussen, G. W. Jordan, M. Akinc, O. Hunter,Jr. and M. F. Berard, "Influence of Precipitation Procedure on Sinterability of $\mathrm{Y}_{2} \mathrm{O}_{3}$ Prepared from Hydroxide Precursor”, Ceram. Int., 9[2], 59-60 (1983)

10M. H. Lewis, The Microstructure of Magnesium Oxide Cleavage Surfaces", Phil. Mag. 13, 1123- 1130(1965)

11F. F. Lange and K. A. D. Lambe, "Interaction Between a crack Front and Cleavage Steps", Phil.Mag., 18, 129-136(1968)

12R. W. Davidge and G. Tappin, "The Effective Surface Energy of Brittle Materials", J. Mater. Sci., 3, 165-173 (1968) 


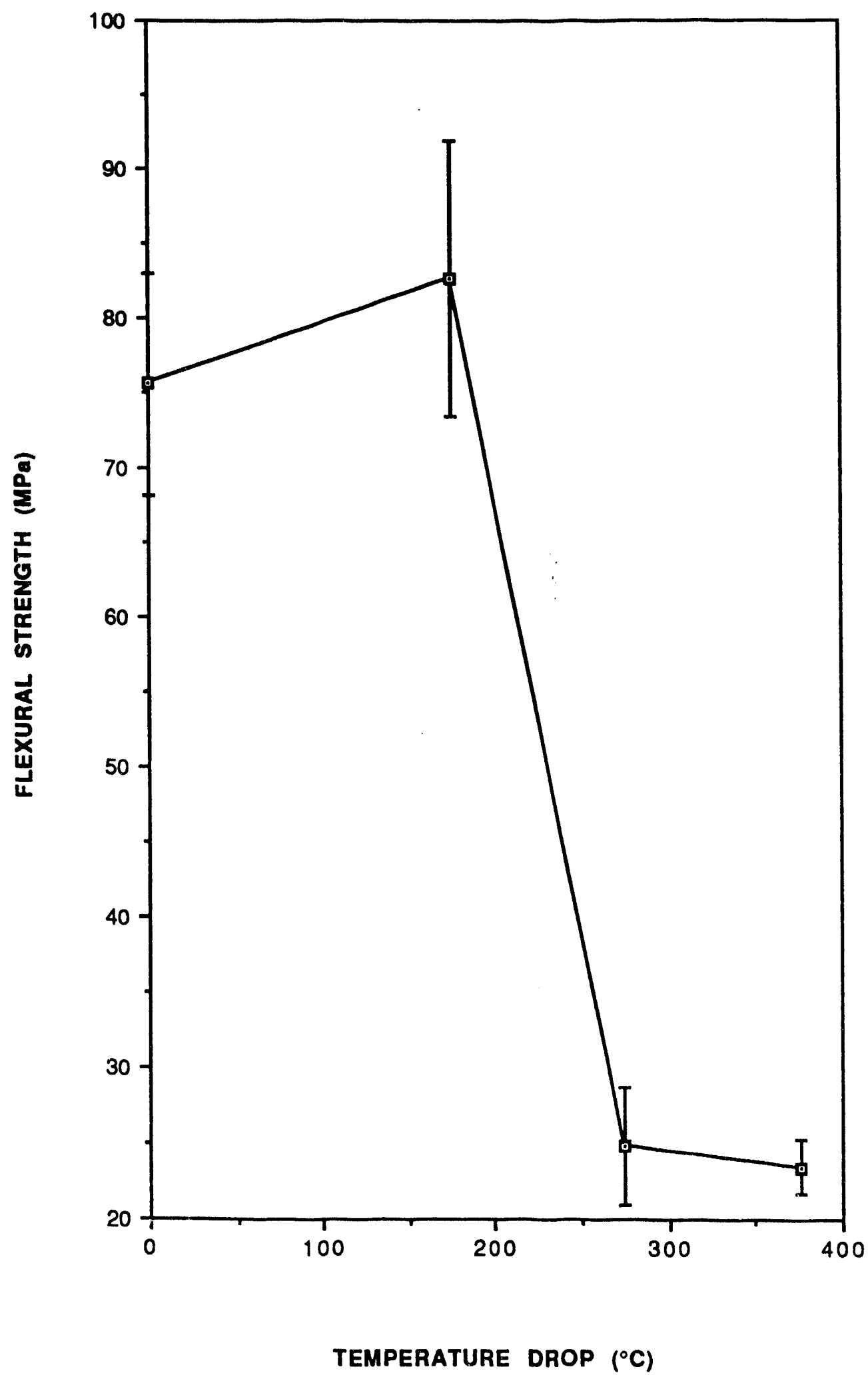

Fig. 1. Thermal shock behavior of vacuum sintered yttria ceramics 


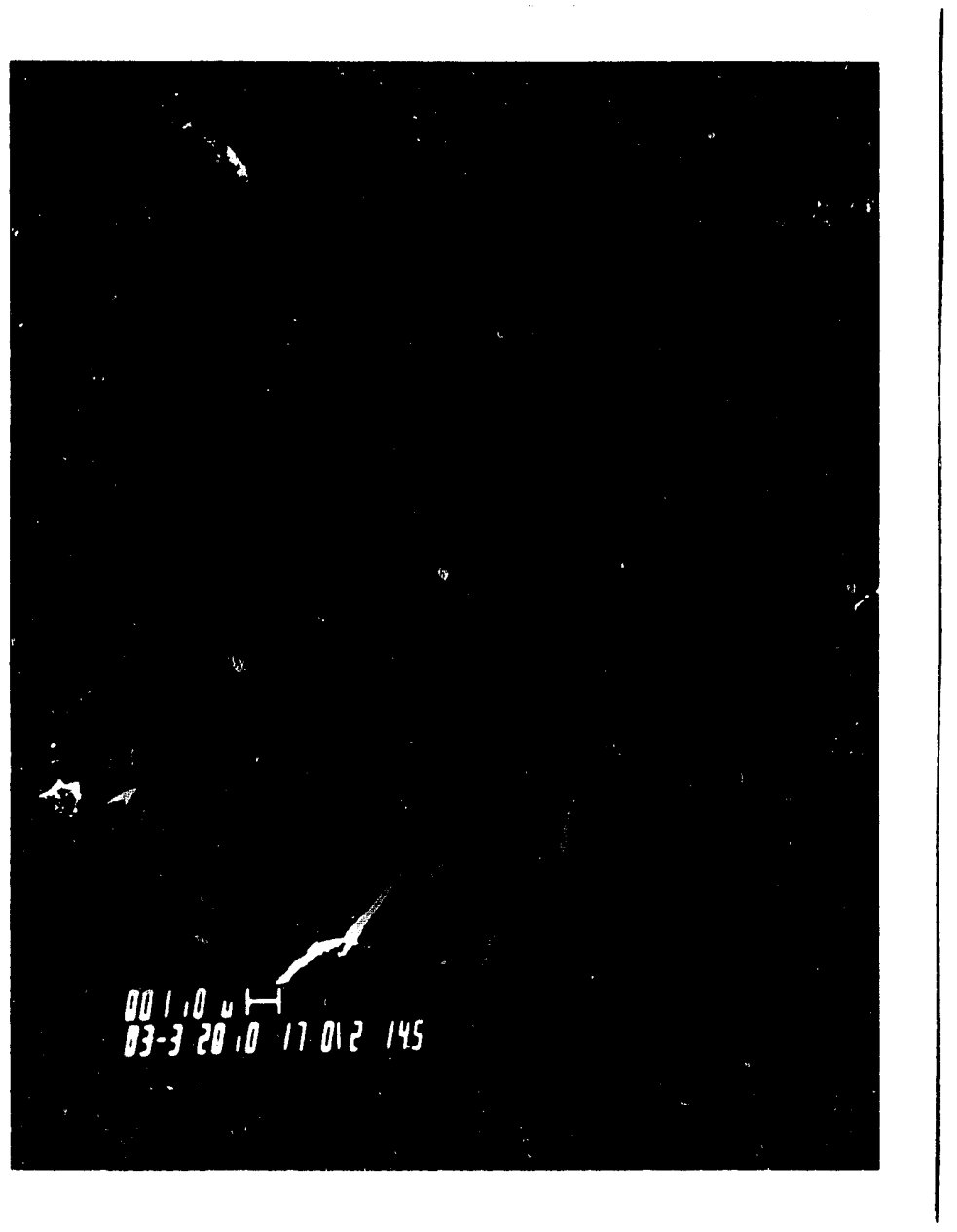

Fig. 2. SEM micrograph of the fractured surface of vacuum sintered yttria ceramics 


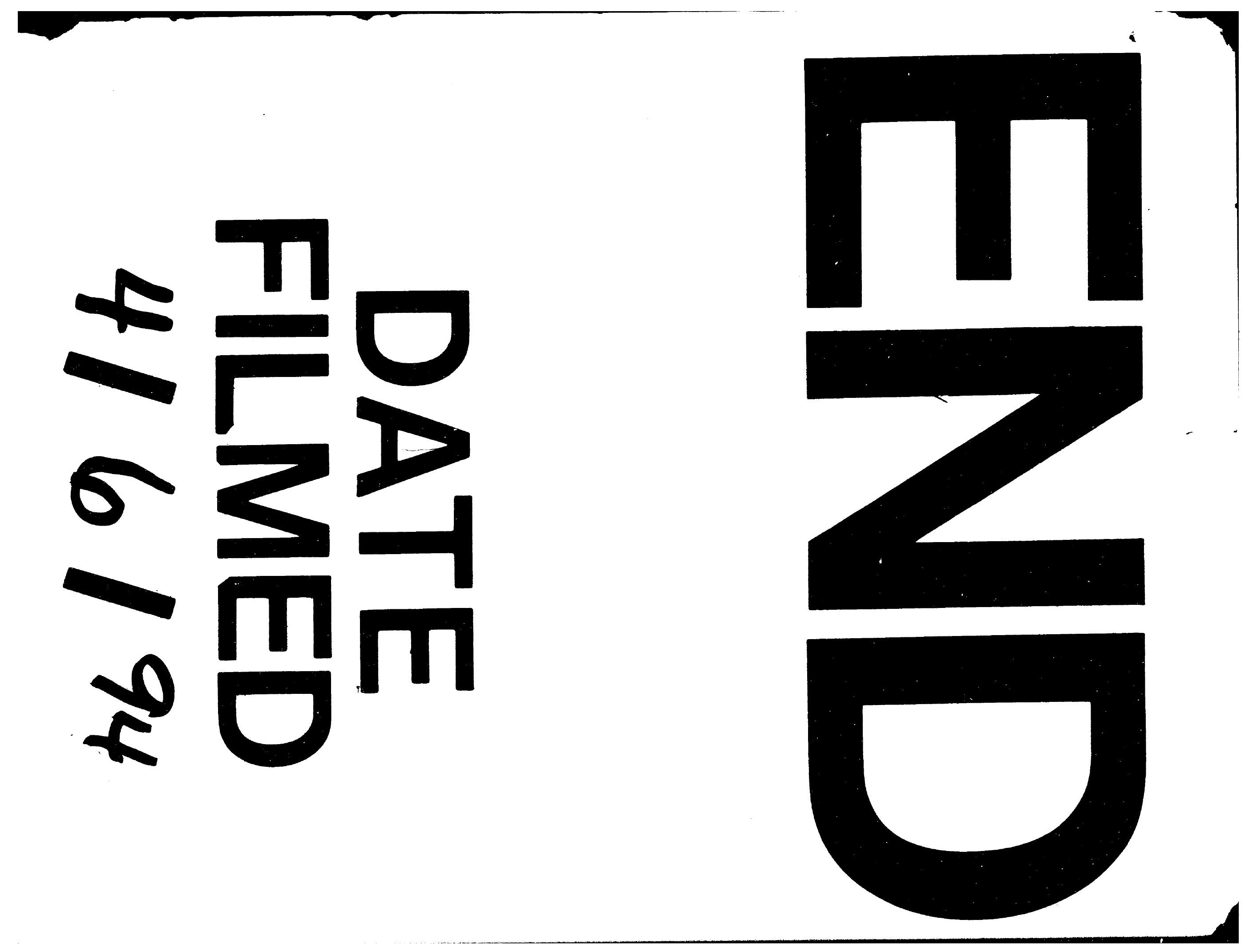


